\title{
The impact of concomitant pulmonary infection on immune dysregulation in Pneumocystis jirovecii pneumonia
}

\author{
Chung-Wei Chou ${ }^{1,2}$, Fang-Chi Lin ${ }^{3,4}$, Han-Chen Tsai ${ }^{5}$ and Shi-Chuan Chang ${ }^{3,6^{*}}$
}

\begin{abstract}
Background: Concurrent infection may be found in Pneumocystis jirovecii pneumonia (PJP) of non-acquired immunodeficiency syndrome (AIDS) patients, however, its impact on immune dysregulation of PJP in non-AIDS patients remains unknown.

Methods: We measured pro-inflammatory cytokines including tumor necrosis factor (TNF)-a, interleukin (IL)-1 $\beta$, IL-8, IL-17, monocyte chemoattractant protein-1 (MCP-1) and anti-inflammatory cytokines including IL-10 and transforming growth factor (TGF)- $\beta 1$ and IL-1 receptor antagonist (IL-1RA) and inflammatory markers including high mobility group box 1, Krebs von den Lungen-6, receptor for advanced glycation end product, advanced glycation end product, surfactant protein D in bronchoalveolar lavage fluid (BALF) and blood in 47 pure PCP and 18 mixed PJP and other pulmonary infections (mixed PJP) in non-AIDS immunocompromised patients and explored their clinical relevance. The burden of Pneumocystis jirovecii in the lung was determined by counting number of clusters of Pneumocystis jirovecii per slide and the concentration of $\beta$-D-glucan in BALF. PJP severity was determined by arterial oxygen tension/fraction of inspired oxygen concentration ratio, the need of mechanical ventilation and death.

Results: Compared with pure PJP group, mixed PJP group had significantly higher BALF levels of IL-1 $\beta$, TNF- $\alpha$ and IL-8 and significantly higher blood levels of IL-8. The BALF ratios of TNF-a/LL-10, IL-8/IL-10, IL-1 $\beta / / L-10$, TNF-a/TGF- $\beta 1$, IL-8/TGF- $\beta 1$, IL-1 $\beta / T G F-\beta 1$ and IL-1 $\beta /$ IL-1RA were significantly higher in mixed than in pure PJP patients. There was no significant difference in clinical features and outcome between pure and mixed PJP groups, including inflammatory biomarkers and the fungal burden. In pure PJP patients, significantly higher BALF levels of IL-8 and the ratios of IL-8/IL-10, IL-1 $\beta / T G F-\beta 1$, MCP-1/TGF- $\beta 1$, MCP-1/IL1RA and IL-8/TGF- $\beta 1$ were found in the patients requiring mechanical ventilation and in non-survivors.
\end{abstract}

Conclusions: In summary, concurrent pulmonary infection might enhance immune dysregulation of PJP in non-AIDS immunocompromised patients, but did not affect the outcome as evidenced by morbidity and mortality. Because of limited number of cases studied, further studies with larger populations are needed to verify these issues.

Keywords: Anti-inflammatory cytokines, Bronchoalveolar lavage fluid, Non-acquired immunodeficiency syndrome, Pneumocystis jirovecii pneumonia, Pro-inflammatory cytokines

\footnotetext{
*Correspondence: scchang@vghtpe.gov.tw

${ }^{3}$ Department of Chest Medicine, Taipei Veterans General Hospital, No. 201,

Section 2, Shih-Pai Road, Taipei 112, Taiwan

${ }^{6}$ Institute of Emergency and Critical Care Medicine, National Yang-Ming Uni-

versity, Taipei, Taiwan

Full list of author information is available at the end of the article
}

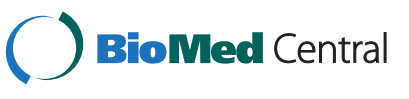

(c) 2014 Chou et al.; licensee BioMed Central Ltd. This is an Open Access article distributed under the terms of the Creative Commons Attribution License (http://creativecommons.org/licenses/by/4.0), which permits unrestricted use, distribution, and reproduction in any medium, provided the original work is properly credited. The Creative Commons Public Domain Dedication waiver (http://creativecommons.org/publicdomain/zero/1.0/) applies to the data made available in this article, unless otherwise stated. 


\section{Background}

Pneumocystis is an opportunistic fungal pathogen that causes Pneumocystis jirovecii pneumonia (PJP). PJP-related morbidity and mortality appear to be a major health problem for patients with acquired immunodeficiency syndrome (AIDS) and for those with immunosuppression resulted from chemotherapy, organ transplantation and long-term treatment with steroid or other immunosuppressants for a variety of diseases [1]. The clinical features, radiological findings, response to treatment and outcome of PJP are reported to be widely different between the patients with or without AIDS $[2,3]$. The reasons underlying the differences in clinical features, radiological findings, treatment response and outcome of PJP between the patients with and without AIDS remain to be elucidated.

Some studies suggest that pathology of PJP inflammatory response is the main factor attributed to morbidity and mortality of PJP patients [4-8], although pathology itself and underlying disorders resulting in impaired immune function are also of clinical importance. Our and previous studies $[9,10]$ indicated that immune dysregulation was found in PJP of the patients with AIDS and non-AIDS, and certain pro-inflammatory cytokine/ anti-inflammatory cytokine ratios in bronchoalveolar lavage fluid (BALF) were of considerable value in assessing the severity of PJP and outcome of the patients [10].

Mixed pulmonary infections including PJP and other pathogens are uncommon in patients with AIDS or non-AIDS immunocompromised hosts. In this study, we intended to explore the impact of concomitant pulmonary infection on immune dysregulation of PJP as evidenced by the changes in pro-inflammatory cytokines and antiinflammatory cytokines and its clinical relevance. Our study results showed concurrent pulmonary infection might enhance immune dysregulation of PJP in nonAIDS immunocompromised patients, but did not affect the outcome as evidenced by morbidity and mortality.

\section{Methods}

\section{Non-AIDS PJP patients}

Sixty five consecutive non-AIDS immunocompromised patients with PJP diagnosed by identification of Pneumocystis jirovecii cysts or trophozoites in Papanicolaou- and Gomori methenamine silver stained-smears of BALF at Taipei Veterans General Hospital from November 1987 to September 2012 were included for this study. The patients were classified into two groups. One group included patients with pure PJP. The other group included those with PJP and concomitant pulmonary infection including cytomegalovirus (CMV) pneumonia and/or co-infections with other pathogens. Peripheral blood samples were collected after bronchoalveolar lavage (BAL) for measurements of cytokines and inflammatory biomarkers. The institutional Review Board of Taipei
Veterans General Hospital approved the study (No: 201009019IC and No: 96-04-02A), and written informed consent was obtained from all patients before entering the study of cytokines and inflammatory biomarkers in BALF and blood.

\section{Diagnostic criteria}

Bacterial pneumonia was diagnosed when a quantitative bacterial culture from BALF samples grew pathogenic bacteria $>10^{4}$ colonies $/ \mathrm{mL}$. CMV was considered to be the pathogen if it was demonstrated on BALF cytology smears or positive result of CMV culture from BALF. Fungal pneumonia was diagnosed when one of the following criteria was met: (1) fungi were identified by microbiologic studies in at least two different lower respiratory tract secretions including BALF; (2) fungi were demonstrated by cytology smears of BALF in the presence of a compatible clinical and chest imaging findings; (3) fungi were demonstrated by histopathological examination of lung biopsy specimens; (4) positive results of blood cultures in the presence of compatible clinical and chest imaging features. Legionella infection was considered when single serum indirect fluorescent antibody titer was $\geqq 1: 256$.

\section{Oxygenation index}

The arterial oxygen tension $\left(\mathrm{PaO}_{2}\right)$ was analyzed with ABL III (Radiometer, Copenhagen, Denmark). Oxygenation index $\left(\mathrm{PaO}_{2} / \mathrm{FiO}_{2}\right.$ ratio) was calculated as $\mathrm{PaO}_{2}$ divided by inspired oxygen fraction $\left(\mathrm{FiO}_{2}\right)$.

\section{BALF and blood samples}

The fiberoptic bronchoscope (Model BF20 or P20; Olympus, Tokyo, Japan) was wedged in the orifice of a lobar or segmental bronchus of the right middle lobe or lingular division or other appropriate location. Diagnostic BAL was done using three aliquots of a $50-\mathrm{mL}$ sterile isotonic sodium chloride. Aspirates were pooled into a siliconized container and kept on ice during transport. Part of the retrieved BALF was subjected to Papanicolaou and Riu's staining routinely. Some slides were stored for subsequent special staining if clinically indicated. A 10-mL sample of venous blood was drawn immediately after BAL. The supernatants of blood and BALF were frozen and stored at $-70^{\circ} \mathrm{C}$ until analyzed.

\section{BALF cell analysis}

BALF for cell analysis was filtered through two-layer sterile gauzes to remove mucus, and then cellular materials were sedimented by centrifugation $(2500 \mathrm{rpm}$ for $10 \mathrm{~min}$ at $4^{\circ} \mathrm{C}$ ) and the supernatant was stored at $-70^{\circ} \mathrm{C}$ for cytokine analysis later. The pellet was re-suspended in $1 \mathrm{ml}$ phosphate buffered saline (PBS) for quantitative cell count. The cell differentials of BALF were measured 
by a hemocytometer (Hausser Scientific, Horsham, PA, USA) for counting at least 200 cells. For analysis of lymphocyte subpopulations $200 \mu \mathrm{l}$ of cell suspensions $\left(2 \times 10^{6}\right.$ cells $)$ were incubated for $40 \mathrm{~min}$ at $4^{\circ} \mathrm{C}$ with $20 \mathrm{ml}$ fluorescein isothiocyanate conjugated monoclonal antibody (Becton Dickinson, San Jose, Ca, USA). Following the incubation, $2 \mathrm{ml}$ of cold PBS was added to the pellet and washed at $2500 \mathrm{rpm}$ for $10 \mathrm{~min}$ at $4^{\circ} \mathrm{C}$. Prepared BALF samples were examined by flow cytometry (FACS Calibur, Becton Dickinson, San Jose, CA, USA).

\section{Measurement of cytokines and biomarkers}

The levels of cytokines in the supernatants of BALF and blood were measured by the commercially available enzyme-linked immunosorbent assay kits: interleukin (IL)-1 $\beta$, tumor necrosis factor (TNF)- $\alpha$, IL-8, monocyte chemoattractant protein (MCP)-1, IL-17, IL-10 and transforming growth factor (TGF)- $\beta 1$, and IL-1 receptor antagonist (IL-1RA) (R\&D Systems; Minneapolis, MN, USA). The levels of biomarkers in the supernatants of BALF and blood were determined by commercial enzyme-linked immunosorbent assay kits according to the manufacturer's instructions: high mobility group box 1 (HMGB1, HMGB1 ELISA kit II; Shino-Test Corporation, Tokyo); Krebs von den Lungen-6 (KL-6, Eisai, Tokyo, Japan); receptor for advanced glycation end product (RAGE, R\&D Systems; Minneapolis, MN, USA); advanced glycation end product (AGE, Cell Biolabs Inc., San Diego, CA, USA); surfactant protein D (SPD, Biovendor, Modrice, Czech Republic). The lower limits of these variables were adapted as follows: IL- $1 \beta, 1 \mathrm{pg} / \mathrm{ml}$; TNF- $\alpha, 4.4 \mathrm{pg} / \mathrm{ml}$; IL-8, 3.5 pg/ml; IL-17, 15 pg/ml; MCP-1, 5.0 pg/ml; IL-10, $3.9 \mathrm{pg} / \mathrm{ml}$; TGF- $\beta 1,4.61 \mathrm{pg} / \mathrm{ml}$; IL-1RA, $6.3 \mathrm{pg} / \mathrm{ml}$; SPD, $0.2 \mathrm{ng} / \mathrm{ml}$; HMGB-1, $1 \mathrm{ng} / \mathrm{ml}$; RAGE, $4.12 \mathrm{pg} / \mathrm{ml}$ and KL-6, $201 \mathrm{U} / \mathrm{ml}$.

\section{Estimating number of Pneumocystis jirovecii fungus in the lung}

This technique was developed by Baughman and his coworkers [11]. Briefly, the BALF specimens $400 \mathrm{ul}$ were spun onto glass slides, using a cytocentrifuge (Cytospin; Shandon Southern Instruments, Sewickley, PA, USA). The slides were air dried and then stained with Riu's stain (modified May-Giemsa stain). The fungal load was semi-quantitatively measured by counting the number of clusters of Pneumocystis jirovecii in relation to 500 nucleated cells per slide.

\section{Measurement of $\beta$-D-glucan}

The concentration of $\beta$-D-glucan was measured by Fungitell assay. It was performed according to the protocol supplied by the manufacturer (Associates of Cape Cod, MA, USA).

\section{Statistical analysis}

Data were expressed as mean and SD or median and interquartile range (IQR), where appropriate. Non-parametric tests were used to analyze the variables because most of them were not normally distributed. Comparisons of the continuous variables between pure PJP and mixed PJP patients were made using the Mann-Whitney U test. Comparisons of the variables in pure PJP patients who were subdivided into two groups based on the variables including oxygenation index, the use of ventilator or survivor status were made using the Mann-Whitney $U$ test. Multivariate analysis was performed using stepwise logistic regression analysis. Comparison for categorical variables between two groups was examined using Chi-squared test and/or Fisher exact, when appropriate. Significance was defined as $\mathrm{p}<0.05$. Statistical analysis was performed using SPSS version 13 (SPSS, Chicago, IL, USA).

\section{Results}

\section{Demographic characteristics, clinical features and cell} profiles in BALF

The demographic characteristics and clinical data of 65 non-AIDS patients. With PJP divided into two groups are shown in Table 1. The oxygenation index, Acute Physiology and Chronic Health Evaluation II scores, intensive care unit (ICU) length of stay, the percentage of ICU admission, use of ventilator and death showed no significant differences between the pure PJP and mixed PJP patients. The concurrent pulmonary infections included bacteria in four cases, aspergillus in one case, CMV in nine cases, cryptococcus in two cases, CMV and aspergillus in one case, and CMV and legionella spp. in one case. The total cell count and cell differentials, and lymphocyte subpopulations in BALF are summarized in Table 2. There were no significant differences in total cell count, cell differentials and lymphocyte subpopulations between PJP patients with and without concurrent pulmonary infection.

\section{Comparisons of BALF and blood cytokines between pure and mixed PJP patients}

The blood IL-1 $\beta$ was not measured because of being undetectable or very low levels based on our previous experience. Comparisons of cytokines in BALF and blood samples between pure PJP and mixed PJP patients are given in Table 3 . The levels of BALF anti-inflammatory cytokines including IL-10, TGF- $\beta 1$ and IL-1RA showed no significant differences between the two groups.

The values of BALF IL- $1 \beta$, TNF- $\alpha$, IL- 8 and the ratios of IL- $1 \beta /$ IL-10, TNF- $\alpha /$ IL-10, IL-8/IL-10, IL-1 $\beta /$ TGF- $\beta 1$, TNF- $\alpha /$ TGF- $\beta 1$, IL- $8 /$ TGF- $\beta 1$ and IL- $1 \beta /$ IL-1RA were significantly higher in mixed PJP than in pure PJP patients. The blood levels of IL-8 were significantly higher in mixed PJP than those in pure PJP patients. 
Table 1 Demographic and clinical characteristics of 65 patients with PJP

\begin{tabular}{|c|c|c|c|}
\hline & Pure PJP & Mixed PJP & P value \\
\hline Gender(M/F) & $25 / 22$ & 9/9 & 0.818 \\
\hline Age, years & $49.1 \pm 16.0$ & $50.6 \pm 17.7$ & 0.587 \\
\hline \multicolumn{4}{|l|}{ Underlying diseases } \\
\hline Hematological malignancy s/p chemotherapy & 6 & 2 & \\
\hline Allogeneic peripheral blood stem cell transplantation & 3 & 2 & \\
\hline Solid organ transplantation (kidney/heart/liver/pancreas/pancreas-kidney) & 19/4/2/1/1 & $3 / 0 / 0 / 0 / 0$ & \\
\hline Connective tissue diseases with immunosuppresants & 6 & 2 & \\
\hline Glomerulonephritis with immunosuppresants & 3 & 6 & \\
\hline Prostate cancer with immunosuppresants & 1 & 0 & \\
\hline Breast cancer with immunosuppresants & 0 & 1 & \\
\hline Long-term steroid therapy & 1 & 1 & \\
\hline DM & 0 & 1 & \\
\hline $\mathrm{PaO}_{2} / \mathrm{FiO}_{2}$ before $\mathrm{BAL}$ & $230.0(182.2 ; 278.7)$ & 245.4(158.3;322.9) & 0.631 \\
\hline APACHE II scores & $23.00(18.00 ; 27.50)$ & $23.50(20.25 ; 26.50)$ & 0.987 \\
\hline ICU admission, case number (\%) & 23(48.9) & $12(66.7)$ & 0.269 \\
\hline ICU length of stay (days) & $19.0(7.3 ; 24.0)$ & 11.0(6.3;21.3) & 0.456 \\
\hline Ventilator needed, case number (\%) & 24(51.1) & $11(61.1)$ & 0.667 \\
\hline Death, case number (\%) & 19(40.4) & $10(55.6)$ & 0.403 \\
\hline
\end{tabular}

Data are expressed as case number and \% in parenthesis or median IQR (25\%;75\%).

$\mathrm{PJP}=$ Pneumocystis jirovecii pneumonia; Mixed PJP = PJP with concurrent other pulmonary infections; $\mathrm{PaO}_{2}=$ arterial oxygen tension; FiO $_{2}=$ fraction of inspired oxygen; ICU = intensive care unit; $\mathrm{BAL}=$ bronchoalveolar lavage; APACHE = Acute Physiology and Chronic Health Evaluation.

\section{Comparisons of BALF and blood inflammatory biomarkers between pure and mixed PJP patients}

No significant differences in the inflammatory biomarkers levels in BALF or blood were observed when pure PJP were compared with mixed PJP patients. The biomarkers included KL-6, SPD, HMGB-1, RAGE and AGE. The results are shown in Additional file 1: Table S1.
Comparisons of cytokines and cytokine ratios in BALF and blood between concurrent bacterial and viral infection in mixed PJP patients

We compared pro-inflammatory cytokines, anti-inflammatory cytokines and ratio of pro-inflammatory cytokines/anti-inflammatory cytokines in both BALF and blood in mixed PJP patients who were divided

Table 2 Comparisons of cell profile and lymphocyte subpopulations in BALF between pure and mixed PJP patients

\begin{tabular}{lccc}
\hline & $\begin{array}{c}\text { Pure PJP } \\
\text { (N =47) }\end{array}$ & $\begin{array}{c}\text { Mixed PJP } \\
(\mathbf{N}=\mathbf{1 8})\end{array}$ & P value \\
\hline Total cell count, $10^{3} / \mathrm{ml}$ & $46.00(21.24 ; 95.16)$ & $30.00(18.27 ; 115.07)$ & 0.560 \\
Macrophages, \% & $67.50(57.00 ; 82.00)$ & $64.25(42.63 ; 71.38)$ & $18.88(10.19 ; 60.15)$ \\
Macrophage count, $10^{3} / \mathrm{ml}$ & $36.23(12.64 ; 53.01)$ & $7.50(1.88 ; 20.38)$ & 0.246 \\
Lymphocytes, \% & $10.25(3.00 ; 29.63)$ & $2.03(1.01 ; 3.47)$ & 0.519 \\
Lymphocyte count, $10^{3} / \mathrm{ml}$ & $3.39(1.18 ; 17.04)$ & $21.50(9.13 ; 33.13)$ & 0.364 \\
Neutrophils, \% & $10.50(4.88 ; 20.88)$ & $7.84(1.46 ; 25.07)$ & 0.283 \\
Neutrophil count, $10^{3} / \mathrm{ml}$ & $3.97(1.84 ; 11.41)$ & $11.50(4.80 ; 22.63)$ & 0.06 \\
CD4/CD8 ratio & $22.30(8.50 ; 37.40)$ & $0.42(0.06 ; 5.73)$ & 0.386 \\
CD4+ cells, \% & $2.48(0.30 ; 8.02)$ & $16.85(8.28 ; 51.48)$ & 0.127 \\
CD4+ cells, $10^{3} / \mathrm{ml}$ & $31.80(15.80 ; 59.70)$ & $0.51(0.21 ; 19.01)$ & 0.302 \\
CD8+ cells, \% & $4.67(0.55 ; 13.19)$ & $0.31(0.18 ; 1.95)$ & 0.384 \\
CD8+ cells, $10^{3} / \mathrm{ml}$ & $0.67(0.31 ; 1.20)$ & & 0.356 \\
\hline
\end{tabular}

Data are expressed as median IQR (25\%;75\%).

$\mathrm{BALF}=$ Bronchoalveolar lavage fluid; $\mathrm{PJP}=$ Pneumocystis jirovecii pneumonia; Mixed PJP $=\mathrm{PJP}$ with concurrent other pulmonary infections

The comparison was made by Mann-Whitney $U$ test. 
Table 3 Comparisons of cytokines in BALF and blood between pure and mixed PJP patients

\begin{tabular}{|c|c|c|c|}
\hline & $\begin{array}{l}\text { Pure PJP } \\
(\mathrm{N}=47)\end{array}$ & $\begin{array}{l}\text { Mixed PJP } \\
(\mathrm{N}=18)\end{array}$ & $P$ value \\
\hline \multicolumn{4}{|l|}{ BALF } \\
\hline $\mathrm{IL}-1 \beta, \mathrm{pg} / \mathrm{ml}$ & $2.13(1.66 ; 2.91)$ & $4.59(1.92 ; 24.45)$ & 0.024 \\
\hline TNF-a, pg/ml & $10.10(8.83 ; 13.08)$ & $12.24(10.09 ; 23.84)$ & 0.026 \\
\hline $\mid \mathrm{L}-8, \mathrm{pg} / \mathrm{ml}$ & $46.30(31.80 ; 175.30)$ & 298.85(110.98;434.63) & 0.001 \\
\hline IL-17, pg/ml & $15.00(15.00 ; 15.00)$ & $15.00(15.00 ; 15.00)$ & 0.883 \\
\hline MCP-1, pg/ml & $1048.50(250.81 ; 2842.70)$ & $1140.25(459.46 ; 2171.44)$ & 0.649 \\
\hline IL-10, pg/ml & $3.90(3.90 ; 7.70)$ & $3.90(3.90 ; 3.90)$ & 0.152 \\
\hline TGF- $\beta 1, \mathrm{pg} / \mathrm{ml}$ & $49.60(42.10 ; 60.30)$ & $46.55(44.88 ; 59.33)$ & 0.899 \\
\hline |L-1RA, pg/ml & $1177.95(609.10 ; 2816.00)$ & $1682.15(1174.78 ; 4496.43)$ & 0.257 \\
\hline$\| L-1 \beta / I L-10$ & $0.48(0.35 ; 0.56)$ & $1.18(0.29 ; 5.22)$ & 0.018 \\
\hline TNF-a/IL-10 & $2.33(1.26 ; 2.64)$ & $2.80(2.43 ; 3.87)$ & 0.011 \\
\hline IL-8/IL-10 & $10.21(4.69 ; 29.44)$ & $53.60(24.49 ; 85.10)$ & 0.001 \\
\hline IL-17/IL-10 & $3.85(3.17 ; 3.85)$ & $3.85(3.85 ; 3.85)$ & 0.698 \\
\hline MCP-1/ IL-10 & $214.87(55.52 ; 362.63)$ & $176.11(117.81 ; 375.97)$ & 0.567 \\
\hline IL-1 $\beta / T G F-\beta 1$ & $0.04(0.02 ; 0.05)$ & $0.11(0.03 ; 0.42)$ & 0.002 \\
\hline TNF- $\alpha / T G F-\beta 1$ & $0.19(0.11 ; 0.25)$ & $0.25(0.22 ; 0.39)$ & 0.004 \\
\hline IL-8/TGF- $\beta 1$ & $0.76(0.28 ; 2.22)$ & $4.85(2.47 ; 9.99)$ & $<0.001$ \\
\hline IL-17/TGF- $\beta 1$ & $0.31(0.26 ; 0.37)$ & $0.27(0.25 ; 0.36)$ & 0.570 \\
\hline MCP-1/TGF- $\beta 1$ & $10.48(0.96 ; 42.87)$ & $18.54(10.85 ; 39.91)$ & 0.182 \\
\hline IL-1 $\beta / I L-1 R A$ & $0.00(0.00 ; 0.00)$ & $0.01(0.00 .0 .02)$ & 0.048 \\
\hline TNF-a/IL-1RA & $0.01(0.00 ; 0.02)$ & $0.01(0.00 ; 0.02)$ & 0.743 \\
\hline IL-8/IL-1RA & $0.06(0.02 ; 0.22)$ & $0.11(0.05 ; 0.76)$ & 0.385 \\
\hline IL-17/IL-1RA & $0.01(0.01 ; 0.03)$ & $0.01(0.00 ; 0.02)$ & 0.385 \\
\hline MCP-1/IL-1RA & $0.99(0.23 ; 1.52)$ & $0.65(0.08 ; 1.59)$ & 0.905 \\
\hline \multicolumn{4}{|l|}{ Blood } \\
\hline TNF-a, pg/ml & $12.00(9.00 ; 17.10)$ & $12.25(7.55 ; 20.68)$ & 0.829 \\
\hline IL-8, pg/ml & $30.41(18.78 ; 53.40)$ & $71.80(32.90 ; 136.33)$ & 0.008 \\
\hline IL-17, pg/ml & 15.00(15.00; 15.00) & 15.00(15.00; 15.00) & 0.832 \\
\hline MCP-1, pg/ml & $1271.70(402.90 ; 2229.20)$ & $1928.80(525.95 ; 3496.50)$ & 0.285 \\
\hline IL-10, pg/ml & $19.90(10.40 ; 37.50)$ & $33.90(9.88 ; 62.53)$ & 0.226 \\
\hline TGF- $\beta 1, \mathrm{pg} / \mathrm{ml}$ & $458.20(245.89 ; 7768.70)$ & $5996.50(259.08 ; 7819.45)$ & 0.288 \\
\hline IL-1RA, pg/ml & $884.00(354.68 ; 2348.75)$ & $2160.40(402.80 ; 6116.50)$ & 0.229 \\
\hline |L-8/IL-10 & $1.73(0.86 ; 2.79)$ & $2.38(0.92 ; 6.05)$ & 0.131 \\
\hline IL-8/TGF- $\beta 1$ & $0.06(0.00 ; 0.21)$ & $0.01(0.00 ; 0.30)$ & 0.895 \\
\hline TNF-a/IL-10 & $0.56(0.35 ; 1.12)$ & $0.35(0.19 ; 1.19)$ & 0.284 \\
\hline TNF- $\alpha / T G F-\beta 1$ & $0.02(0.00 ; 0.07)$ & $0.00(0.00 ; 0.07)$ & 0.215 \\
\hline
\end{tabular}

Data are expressed as median IQR (25\%;75\%).

$\mathrm{BALF}=$ Bronchoalveolar lavage fluid; PJP = Pneumocystis jirovecii pneumonia; Mixed PJP = PJP with concurrent other pulmonary infections; IL = Interleukin; TGF- $\beta 1=$ Transforming growth factor- $\beta 1$; TNF- $\alpha=$ Tumor necrosis factor- $\alpha$; MCP-1 = Monocyte chemoattractant protein-1; IL-1RA = IL-1 receptor antagonist. The comparison was made by Mann-Whitney $\mathrm{U}$ test.

into concurrent pulmonary bacterial and viral infection groups. The results showed no significant differences in the variables measured except for that BALF IL-1 $\beta / I L-1 R A$ ratio were significantly higher in bacterial infection group. The results are shown in Additional file 2: Table S2.
Comparisons of Pneumocystis jirovecii burden in the lung The median number of Pneumocystis jirovecii in the lung was 3 (IQR, 1;7) in pure PJP and 2.5 (IQR, 1;12) in mixed PJP patients. There was no significant difference between the two groups. The median levels of BALF $\beta$ - 
D-glucan in pure and mixed PJP patients were 203.30 (IQR, 148.30;442.40) and 260.60 (IQR, 134.40;623.40), respectively. The median levels of serum $\beta$-D-glucan in pure and mixed PJP patients were 213.00 (IQR, 19.90;784.50) and 215.65 (IQR, 75.45;7103.00), respectively. The values of BALF and serum $\beta$-D-glucan were not significantly different between the two groups.

\section{Comparisons of cytokines and pro-inflammatory/anti- inflammatory cytokine ratios between pure PJP patients divided into groups by oxygenation index $\left(\mathrm{PaO}_{2} / \mathrm{FiO}_{2}\right)$, the use of ventilator and outcome}

Comparisons between pure PJP patients with $\mathrm{PaO}_{2} / \mathrm{FiO}_{2}>$ $200 \mathrm{mmHg}$ and $\mathrm{PaO}_{2} / \mathrm{FiO}_{2} \leq 200 \mathrm{mmHg}$ are shown in Table 4. Compared to the patients with $\mathrm{PaO}_{2} / \mathrm{FiO}_{2}>$ $200 \mathrm{mmHg}$, those with $\mathrm{PaO}_{2} / \mathrm{FiO}_{2} \leq 200 \mathrm{mmHg}$ had significantly higher BALF levels of IL-1RA, ratios of IL- $1 \beta /$ TGF- $\beta 1$, TNF- $\alpha /$ TGF- $\beta 1$, IL-8/TGF- $\beta 1$ and MCP$1 / \mathrm{TGF}-\beta 1$, and had significantly higher blood levels of TGF- $\beta 1$ and ratios of IL-8/IL-10 and TNF- $\alpha / \mathrm{IL}-10$. The ratios of IL-8/TGF- $\beta 1$ and TNF- $\alpha /$ TGF- $\beta 1$ in blood was significantly lower in those with $\mathrm{PaO}_{2} / \mathrm{FiO}_{2} \leq 200 \mathrm{mmHg}$. However, after stepwise logistic regression analysis, none of these variables was independent factor.

Compared with pure PJP patients without ventilator, BALF levels of IL-8 were significantly higher and the values of IL-10 were markedly lower in pure PJP patients with ventilator. BALF ratios of IL-8/IL-10, IL-1 $\beta /$ TGF$\beta 1$, TNF- $\alpha /$ TGF- $\beta 1$, IL-8/TGF- $\beta 1$, MCP-1/TGF- $\beta 1$ and MCP-1/IL-1RA, and blood levels of IL- 8 and IL-10 and were significantly higher in pure PJP patients with ventilator. The TNF- $\alpha / \mathrm{IL}-10$ ratio in blood was significantly lower in those with ventilator (Table 5). However, after stepwise logistic regression analysis, only BALF IL-8 was the independent factor ( $\mathrm{p}=0.023,95 \%$ confident interval [CI $]=0.000-0.004)$.

Similar findings could be found in pure PJP patients who were divided into subgroups by clinical outcome. Compared with survivors, the non-survivors had significantly higher BALF values of IL-8 and ratios of IL-8/IL10, IL-1 $\beta /$ TGF- $\beta 1$, IL-8/TGF- $\beta 1$, MCP- $1 /$ TGF- $\beta 1$, IL-8/ IL-1RA and MCP-1/IL-1RA, and significantly higher blood levels of IL-10 and IL-8. The blood level of IL-1RA was significantly lower in non-survivors (Table 6). However, after stepwise logistic regression analysis, only BALF IL-8/TGF- $\beta 1$ was the independent factor $(\mathrm{p}=0.018$, 95\% CI $=0.022-0.186$ ).

\footnotetext{
Comparisons of cytokines and pro-inflammatory/antiinflammatory cytokine ratios between mixed PJP patients divided into groups by oxygenation index $\left(\mathrm{PaO}_{2} / \mathrm{FiO}_{2}\right)$, the use of ventilator and outcome

There were no significant differences in BALF and blood levels of cytokines and pro-inflammatory/anti-inflammatory
}

cytokine ratios between mixed PJP patients divided into two groups by oxygenation index and the use of ventilator. Compared with survived mixed PJP patients, BALF values of IL- $1 \beta$, TGF- $\beta 1$, IL-1 $\beta /$ IL-1RA ratio were significantly higher, and blood levels of TGF- $\beta 1$ were markedly lower in the deceased ones.

\section{Discussion}

Few studies discussed the difference in outcomes between pure PJP and PJP with concurrent pulmonary infection in non-AIDS immunocompromised patients. Most of the papers were focused on the CMV co-infection in HIV patients. However, the reported effect of concurrent CMV pneumonia on the outcome of AIDS patients with PJP was controversial. Some studies indicated that the morbidity and mortality showed no significant differences between HIV-infected PJP patients with or without concurrent CMV infection [12-15]. In contrast, AIDS patients with PJP who had co-infection with CMV pneumonia in other studies had higher mortality than those with PJP only $[16,17]$.

The role of concurrent CMV pneumonia in non-AIDS patients with PJP has not yet been well investigated. Miles et al. reported high mortality in non-HIV PJP patients irrespective of whether they had CMV pneumonia or not [15], but their case number was limited. Recently, Kim and coworkers reported that concomitant pulmonary CMV infection did not significantly affect the outcome of PJP with respect to the morbidity and mortality in non-HIV-infected patients with PJP [18]. To the best of our knowledge, this is the first study to compare the outcomes of non-AIDS PJP patients with or without concurrent pulmonary infections, including CMV pneumonia. Our results showed no significant differences in the morbidity and mortality between the two groups of patients (Table 1). Because the studied cases of PJP with concurrent pulmonary infection were limited and CMV pneumonia appeared to be the most common concurrent pulmonary infection, further studies with larger populations are needed to verify these issues.

Theoretically, exaggeration of pro-inflammatory or anti-inflammatory cytokine response may result in excessive inflammation leading to host tissue damage and affect the outcome of the patients. The results of our previous study indicated that as compared with normal lung group, PJP patients had significantly higher levels of pro-inflammatory cytokines and unvaried anti-inflammatory cytokines, and some pro-inflammatory/ anti-inflammatory cytokine ratios were of value in assessing the severity of PJP and in predicting the outcome of the patients [10]. In the current study, the inflammatory cellular responses, as reflected by total cell counts, cell differentials and lymphocyte subpopulation in BALF, between pure PJP and mixed PJP patients showed no 
Table 4 Comparisons of pro-inflammatory and anti-inflammatory cytokines in BALF and blood between pure PJP patients with $\mathrm{PaO}_{2} / \mathrm{FiO}_{2} \leq 200$ and $>200 \mathrm{mmHg}$

$\mathrm{PaO}_{2} / \mathrm{FiO}_{2}$
$>200 \mathrm{mmHg}(\mathrm{N}=24)$

BALF

IL-1 $\beta, \mathrm{pg} / \mathrm{ml}$

TNF-a, pg/ml

IL-8, pg/ml

IL-17, pg/ml

MCP-1, pg/ml

IL-10, pg/ml

TGF- $\beta 1, p g / m$

IL-1RA, pg/ml

IL-1 $\beta / I L-10$

TNF-a/LL-10

$\mathrm{IL}-8 / \mathrm{IL}-10$

IL-17/IL-10

MCP-1/ IL-10

IL-1 $\beta / T G F-\beta 1$

TNF- $\alpha /$ TGF- $\beta 1$

IL-8/TGF- $\beta 1$

IL-17/TGF- $\beta 1$

MCP-1/TGF- $\beta 1$

IL-1B/IL-1RA

TNF-a/IL-1RA

IL-8/IL-1RA

IL-17/IL-1RA

MCP-1/LL-1RA

Blood

TNF-a, pg/ml

IL-8, pg/ml

IL-17, pg/ml

MCP-1, pg/ml

IL-10, pg/ml

TGF- $\beta 1, p g / m l$

IL-1RA, pg/ml

IL-8/IL-10

|L-8/TGF- $\beta 1$

TNF- $\alpha /$ IL-10

TNF-a/TGF- $\beta 1$

$2.24(1.85 ; 2.86)$
$10.09(7.82 ; 12.44)$
$48.40(24.38 ; 168.25)$
$15.00(15.00 ; 15.00)$
$1066.50(663.37 ; 2593.31)$
$4.25(3.90 ; 8.93)$
$53.40(45.45 ; 128.30)$
$709.70(463.30 ; 1730.20)$
$0.41(0.29 ; 0.57)$
$2.33(1.19 ; 2.63)$
$8.83(3.67 ; 32.04)$
$3.85(2.84 ; 3.85)$
$220.15(110.95 ; 334.84)$
$0.03(0.01 ; 0.05)$
$0.16(0.03 ; 0.22)$
$0.63(0.16 ; 1.84)$
$0.29(0.27 ; 0.33)$
$14.13(4.40 ; 34.32)$
$0.00(0.00 ; 0.01)$
$0.02(0.01 ; 0.04)$
$0.18(0.02 ; 0.99)$
$0.02(0.01 ; 0.03)$
$0.99(0.24 ; 4.05)$

14.50(10.60;17.50)

$33.81(18.85 ; 78.35)$

$15.00(15.00 ; 15.00)$

$1557.80(792.83 ; 2655.05)$

$33.40(12.25 ; 56.93)$

$255.15(168.10 ; 3908.20)$

1087.90(297.10;2697.80)

$1.22(0.59 ; 1.76)$

$0.12(0.04 ; 0.48)$

$0.35(0.17 ; 0.93)$

$0.07(0.02 ; 0.24)$

$\mathrm{PaO}_{2} / \mathrm{FiO}_{2}$ $\leq 200 \mathrm{mmHg}(\mathrm{N}=9)$

P value*

P value

$\leq 200 \mathrm{mmHg}(\mathrm{N}=9)$

\begin{tabular}{|c|c|c|}
\hline $2.65(2.00 ; 5.32)$ & 0.414 & \\
\hline $13.08(9.52 ; 17.82)$ & 0.154 & \\
\hline $175.30(35.00 ; 342.90)$ & 0.193 & \\
\hline $15.00(15.00 ; 15.00)$ & 0.645 & \\
\hline 2453.16(715.00;4288.47) & 0.254 & \\
\hline $3.90(3.90 ; 8.12)$ & 0.414 & \\
\hline $43.90(42.10 ; 51.70)$ & 0.150 & \\
\hline 1835.20(929.33;2816.00) & 0.045 & 0.144 \\
\hline $0.54(0.40 ; 1.36)$ & 0.238 & \\
\hline $2.44(2.06 ; 3.50)$ & 0.179 & \\
\hline 28.22(8.78;53.10) & 0.166 & \\
\hline $3.85(2.42 ; 3.85)$ & 0.547 & \\
\hline 629.02(170.28;914.57) & 0.131 & \\
\hline $0.06(0.03 ; 0.13)$ & 0.026 & 0.741 \\
\hline $0.23(0.22 ; 0.37)$ & 0.003 & 0.421 \\
\hline $3.26(0.80 ; 7.94)$ & 0.032 & 0.787 \\
\hline $0.36(0.29 ; 0.38)$ & 0.121 & \\
\hline $58.27(13.32 ; 107.14)$ & 0.032 & 0.158 \\
\hline $0.00(0.00 ; 0.00)$ & 0.210 & \\
\hline $0.01(0.00 ; 0.01)$ & 0.121 & \\
\hline $0.07(0.02 ; 0.12)$ & 0.374 & \\
\hline $0.01(0.01 ; 0.02)$ & 0.140 & \\
\hline $1.48(0.46 ; 1.52)$ & 0.750 & \\
\hline $12.70(8.50 ; 24.20)$ & 0.640 & \\
\hline $41.20(21.60 ; 90.55)$ & 0.766 & \\
\hline $15.00(15.00 ; 15.00)$ & 0.643 & \\
\hline 1382.60(318.75;2337.80) & 0.512 & \\
\hline 20.80(9.65;32.95) & 0.111 & \\
\hline 479.90(1020.85;10050.65) & 0.014 & 0.892 \\
\hline 701.80(286.90;2375.60) & 0.938 & \\
\hline $2.79(1.14 ; 4.14)$ & 0.020 & 0.903 \\
\hline $0.02(0.01 ; 0.04)$ & 0.020 & 0.787 \\
\hline $0.72(0.43 ; 1.34)$ & 0.035 & 0.872 \\
\hline $0.00(0.00 ; 0.03)$ & 0.012 & 0.233 \\
\hline
\end{tabular}

Data are expressed as median IQR (25\%;75\%)

$\mathrm{PaO}_{2} / \mathrm{FiO}_{2}=$ arterial oxygen tension/fraction of inspired oxygen; $\mathrm{BALF}=$ Bronchoalveolar lavage fluid; $\mathrm{PJP}=$ Pneumocystis jirovecii pneumonia; $\mathrm{IL}=\mathrm{Interleukin}$; TGF- $\beta 1=$ Transforming growth factor- $\beta 1$; TNF- $\alpha=$ Tumor necrosis factor- $\alpha$; MCP-1 = Monocyte chemoattractant protein-1; IL-1RA = IL-1 receptor antagonist.

The comparison was made by Mann-Whitney $U$ test.

$\mathrm{P}^{*}$ : univariate analysis, $\mathrm{P}^{\#}$ : multivariate analysis.

significant differences (Table 2). The levels of inflammatory biomarkers in BALF and blood also did not demonstrate significant differences between two groups of patients.
An imbalance of pro-inflammatory/anti-inflammatory cytokines was shown to be more exacerbated in mixed PJP than in pure PJP patients (Table 3). However, our 
Table 5 Comparisons of pro-inflammatory and anti-inflammatory cytokines in BALF and blood between pure PJP patients with and without ventilator

\begin{tabular}{|c|c|c|c|c|}
\hline & $\begin{array}{l}\text { Without ventilator } \\
\qquad(\mathrm{N}=22)\end{array}$ & $\begin{array}{l}\text { With ventilator } \\
(\mathrm{N}=25)\end{array}$ & P value* & P value $^{\#}$ \\
\hline \multicolumn{5}{|l|}{ BALF } \\
\hline $\mathrm{IL}-1 \beta, \mathrm{pg} / \mathrm{ml}$ & $2.23(1.73 ; 2.91)$ & $2.10(1.53 ; 3.46)$ & 0.915 & \\
\hline TNF-a, pg/ml & $9.81(7.23 ; 14.31)$ & $10.30(9.09 ; 12.84)$ & 0.332 & \\
\hline $\mid \mathrm{L}-8, \mathrm{pg} / \mathrm{ml}$ & $35.63(22.28 ; 70.59)$ & $59.90(32.95 ; 249.65)$ & 0.023 & 0.043 \\
\hline IL-17, pg/ml & $15.00(15.00 ; 15.00)$ & $15.00(15.00 ; 15.00)$ & 0.876 & \\
\hline MCP-1, pg/ml & $847.20(114.46 ; 3158.55)$ & $1048.50(326.90 ; 2761.43)$ & 0.565 & \\
\hline $\mathrm{IL}-10, \mathrm{pg} / \mathrm{ml}$ & $5.33(3.90 ; 9.25)$ & $3.90(3.90 ; 5.50)$ & 0.049 & 0.954 \\
\hline TGF- $\beta 1, p g / m l$ & $53.40(42.10 ; 707.20)$ & $48.80(42.10 ; 55.10)$ & 0.203 & \\
\hline IL-1RA, pg/ml & $1323.10(566.70 ; 3432.50)$ & $1142.20(632.70 ; 2303.10)$ & 0.678 & \\
\hline IL-1 $\beta / I L-10$ & $0.39(0.26 ; 0.55)$ & $0.49(0.37 ; 0.57)$ & 0.119 & \\
\hline TNF-a/IL-10 & $2.23(1.11 ; 2.58)$ & $2.51(2.06 ; 2.71)$ & 0.098 & \\
\hline IL-8/IL-10 & $7.24(3.31 ; 12.42)$ & $15.36(8.26 ; 48.67)$ & 0.004 & 0.733 \\
\hline IL-17/IL-10 & $3.85(3.12 ; 3.85)$ & $3.85(2.84 ; 3.85)$ & 0.981 & \\
\hline MCP-1/ IL-10 & $103.17(28.60 ; 402.18)$ & $262.10(74.72 ; 397.89)$ & 0.172 & \\
\hline IL-1 $\beta / T G F-\beta 1$ & $0.03(0.00 ; 0.05)$ & $0.04(0.03 ; 0.07)$ & 0.018 & 0.545 \\
\hline TNF-a/TGF- $\beta 1$ & $0.13(0.01 ; 0.25)$ & $0.21(0.18 ; 0.26)$ & 0.017 & 0.321 \\
\hline IL-8/TGF- $\beta 1$ & $0.47(0.07 ; 1.02)$ & $1.35(0.73 ; 5.61)$ & $<0.001$ & 0.707 \\
\hline IL-17/TGF- $\beta 1$ & $0.29(0.08 ; 0.46)$ & $0.31(0.27 ; 0.36)$ & 0.793 & \\
\hline MCP-1/TGF- $\beta 1$ & $5.13(0.50 ; 36.72)$ & $21.51(5.32 ; 56.99)$ & 0.023 & 0.369 \\
\hline IL-1 $\beta /$ /L-1RA & $0.00(0.00 ; 0.01)$ & $0.00(0.00 ; 0.00)$ & 0.649 & \\
\hline TNF-a/IL-1RA & $0.01(0.00 ; 0.02)$ & $0.01(0.00 ; 0.02)$ & 0.756 & \\
\hline IL-8/IL-1RA & $0.03(0.01 ; 0.08)$ & $0.10(0.02 ; 0.40)$ & 0.126 & \\
\hline IL-17/IL-1RA & $0.02(0.00 ; 0.03)$ & $0.01(0.01 ; 0.03)$ & 0.943 & \\
\hline MCP-1/IL-1RA & $0.24(0.03 ; 0.70)$ & $1.47(0.28 ; 1.85)$ & 0.011 & 0.582 \\
\hline \multicolumn{5}{|l|}{ Blood } \\
\hline TNF-a, pg/ml & $9.90(8.30 ; 17.10)$ & $12.45(10.20 ; 17.15)$ & 0.123 & \\
\hline $\mid \mathrm{L}-8, \mathrm{pg} / \mathrm{ml}$ & $22.30(14.23 ; 40.75)$ & $42.70(22.95 ; 105.15)$ & 0.004 & 0.969 \\
\hline IL-17, pg/ml & $15.00(15.00 ; 15.00)$ & $15.00(15.00 ; 15.00)$ & 0.866 & \\
\hline MCP-1, pg/ml & $931.65(368.58 ; 1719.33)$ & $1382.60(459.80 ; 2485.55)$ & 0.354 & \\
\hline $\mathrm{IL}-10, \mathrm{pg} / \mathrm{ml}$ & $11.21(9.33 ; 21.60)$ & $32.90(13.35 ; 47.25)$ & 0.006 & 0.938 \\
\hline TGF- $\beta 1, p g / m l$ & $260.35(225.00 ; 11506.09)$ & $557.50(269.85 ; 5782.80)$ & 0.898 & \\
\hline IL-1RA, pg/ml & $2114.30(693.50 ; 3696.90)$ & $701.80(286.90 ; 2117.70)$ & 0.169 & \\
\hline IL-8/IL-10 & $1.83(0.80 ; 2.61)$ & $1.71(0.94 ; 2.81)$ & 0.966 & \\
\hline IL-8/TGF- $\beta 1$ & $0.04(0.00 ; 0.15)$ & $0.10(0.01 ; 0.23)$ & 0.159 & \\
\hline TNF-a/IL-10 & $1.10(0.65 ; 1.31)$ & $0.45(0.25 ; 0.74)$ & 0.022 & 0.160 \\
\hline TNF- $\alpha / T G F-\beta 1$ & $0.00(0.00 ; 1.80)$ & $0.03(0.00 ; 0.07)$ & 0.540 & \\
\hline
\end{tabular}

Data are expressed as median IQR (25\%;75\%).

$\mathrm{BALF}=$ Bronchoalveolar lavage fluid; PJP = Pneumocystis jirovecii pneumonia; IL = Interleukin; TGF- $\beta 1$ = Transforming growth factor $-\beta 1$; TNF- $\alpha=$ Tumor necrosis factor- $\alpha$; MCP-1 = Monocyte chemoattractant protein-1; IL-1RA = IL-1 receptor antagonist.

The comparison was made by Mann-Whitney $U$ test.

$\mathrm{P}^{*}$ : univariate analysis, $\mathrm{P}^{\#}$ : multivariate analysis.

results failed to show significant differences in the morbidity and mortality between the two groups. It remains unclear why there should be limited impact of concurrent pulmonary infection on the cell profiles of BALF and related immune responses involved in PJP of non-AIDS immunocompromised patients. 
Table 6 Comparisons of pro-inflammatory and anti-inflammatory cytokines in BALF and blood between survivors and non-survivors of pure PJP patients

\begin{tabular}{|c|c|c|c|c|}
\hline & $\begin{array}{c}\text { Survivor } \\
(\mathrm{N}=\mathbf{2 8})\end{array}$ & $\begin{array}{l}\text { Non-survivor } \\
(\mathrm{N}=19)\end{array}$ & P value* & P value $^{\#}$ \\
\hline \multicolumn{5}{|l|}{ BALF } \\
\hline $\mathrm{IL}-1 \beta, \mathrm{pg} / \mathrm{ml}$ & $2.21(1.68 ; 3.51)$ & $2.00(1.50 ; 2.91)$ & 0.948 & \\
\hline TNF-a, pg/ml & $10.07(7.98 ; 14.05)$ & $10.10(9.07 ; 11.60)$ & 0.761 & \\
\hline $\mathrm{IL}-8, \mathrm{pg} / \mathrm{ml}$ & $35.63(22.60 ; 79.26)$ & $114.80(36.70 ; 375.60)$ & 0.010 & 0.694 \\
\hline IL-17, pg/ml & $15.00(15.00 ; 15.00)$ & $15.00(15.00 ; 15.00)$ & 0.751 & \\
\hline MCP-1, pg/ml & 736.49(218.78;2703.81) & $1065.50(344.00 ; 3069.70)$ & 0.474 & \\
\hline IL-10, pg/ml & $4.61(3.90 ; 8.89)$ & $3.90(3.90 ; 4.40)$ & 0.079 & \\
\hline TGF- $\beta 1, \mathrm{pg} / \mathrm{ml}$ & $53.40(43.00 ; 194.80)$ & $48.80(41.20 ; 54.13)$ & 0.094 & \\
\hline IL-1RA, pg/ml & $1589.90(669.20 ; 3178.55)$ & $1077.40(512.40 ; 1870.50)$ & 0.254 & \\
\hline $\mathrm{IL}-1 \beta / \mathrm{IL}-10$ & $0.41(0.28 ; 0.56)$ & $0.49(0.36 ; 0.57)$ & 0.293 & \\
\hline TNF-a/IL-10 & $2.33(1.15 ; 2.63)$ & $2.51(2.20 ; 2.71)$ & 0.193 & \\
\hline IL-8/IL-10 & $8.26(3.66 ; 13.75)$ & $17.79(8.90 ; 54.86)$ & 0.002 & 0.735 \\
\hline IL-17/IL-10 & $3.85(3.48 ; 3.85)$ & $3.85(2.27 ; 3.85)$ & 0.451 & \\
\hline MCP-1/ IL-10 & $112.85(39.67 ; 334.84)$ & $273.21(79.44 ; 433.15)$ & 0.146 & \\
\hline IL-1 $\beta / T G F-\beta 1$ & $0.03(0.00 ; 0.05)$ & $0.04(0.03 ; 0.06)$ & 0.042 & 0.611 \\
\hline TNF- $\alpha / T G F-\beta 1$ & $0.15(0.01 ; 0.26)$ & $0.21(0.18 ; 0.25)$ & 0.091 & \\
\hline IL-8/TGF- $\beta 1$ & $0.51(0.13 ; 1.03)$ & $1.56(0.71 ; 7.73)$ & 0.001 & 0.018 \\
\hline IL-17/TGF- $\beta 1$ & $0.28(0.23 ; 0.41)$ & $0.31(0.27 ; 0.36)$ & 0.505 & \\
\hline MCP-1/TGF- $\beta 1$ & $6.09(0.54 ; 39.10)$ & $21.57(5.49 ; 58.27)$ & 0.044 & 0.486 \\
\hline IL-1 $\beta / I L-1 R A$ & $0.00(0.00 ; 0.00)$ & $0.00(0.00 ; 0.01)$ & 0.451 & \\
\hline TNF-a/IL-1RA & $0.01(0.00 ; 0.02)$ & $0.01(0.00 ; 0.02)$ & 0.354 & \\
\hline IL-8/IL-1RA & $0.04(0.01 ; 0.09)$ & $0.12(0.03 ; 0.53)$ & 0.033 & 0.517 \\
\hline IL-17/IL-1RA & $0.01(0.00 ; 0.03)$ & $0.01(0.01 ; 0.03)$ & 0.591 & \\
\hline MCP-1/IL-1RA & $0.28(0.18 ; 1.14)$ & $1.48(0.46 ; 4.43)$ & 0.012 & 0.329 \\
\hline \multicolumn{5}{|l|}{ Blood } \\
\hline TNF-a, pg/ml & $11.10(8.56 ; 18.20)$ & $13.35(10.03 ; 16.45)$ & 0.335 & \\
\hline $\mathrm{IL}-8, \mathrm{pg} / \mathrm{ml}$ & $23.65(16.53 ; 41.55)$ & $47.10(26.80 ; 136.60)$ & 0.002 & 0.397 \\
\hline IL-17, pg/ml & $15.00(15.00 ; 15.00)$ & $15.00(15.00 ; 15.00)$ & 0.781 & \\
\hline $\mathrm{MCP}-1, \mathrm{pg} / \mathrm{ml}$ & $1287.20(374.63 ; 2124.20)$ & $1014.60(529.10 ; 2683.20)$ & 0.537 & \\
\hline IL-10, pg/ml & 14.05(8.78;26.62) & $33.00(11.60 ; 47.10)$ & 0.018 & 0.952 \\
\hline TGF- $\beta 1, p g / m l$ & $1020.85(245.89 ; 10269.20)$ & $423.40(205.00 ; 6450.50)$ & 0.515 & \\
\hline IL-1RA, pg/ml & $1678.75(695.58 ; 3536.63)$ & $565.70(271.33 ; 1594.93)$ & 0.036 & \\
\hline IL-8/IL-10 & $1.74(0.81 ; 2.45)$ & $1.73(1.25 ; 4.05)$ & 0.423 & \\
\hline IL-8/TGF- $\beta 1$ & $0.03(0.00 ; 0.12)$ & $0.12(0.02 ; 0.24)$ & 0.054 & \\
\hline TNF-a/IL-10 & $0.93(0.43 ; 1.23)$ & $0.45(0.24 ; 0.80)$ & 0.083 & \\
\hline TNF- $\alpha / T G F-\beta 1$ & $0.01(0.00 ; 0.06)$ & $0.05(0.00 ; 0.09)$ & 0.273 & \\
\hline
\end{tabular}

Data are expressed as median IQR (25\%;75\%).

$\mathrm{BALF}=$ Bronchoalveolar lavage fluid; $\mathrm{PJP}=$ Pneumocystis jirovecii pneumonia; IL = Interleukin; TGF- $\beta 1=$ Transforming growth factor- $\beta 1 ; \mathrm{TNF}-\mathrm{a}=$ Tumor necrosis factor-a; MCP-1 = Monocyte chemoattractant protein-1; IL-1RA = IL-1 receptor antagonist.

The comparison was made by Mann-Whitney $U$ test.

$\mathrm{P}^{*}$ :univariate analysis, $\mathrm{P}^{\#}$ :multivariate analysis.

Further studies with larger populations are needed to verify these issues.

$\mathrm{T}$ helper (Th) 17 cells, a subset of $\mathrm{T}$ helper cells, appear to play an important role in fungal clearance and defense [19,20]. Impaired IL-17 response was reported to be associated with decreased clearance of Candida and Aspergillus [21,22]. However, the role of IL-17 response in pneumocystis infection has not yet been well 
investigated. The study conducted by Rudner et al. showed decreased levels of IL-17 in the lungs caused by IL-23 deficiency or by neutralizing anti-IL-17 antibody resulted in transient decrease (three weeks after infection) in clearance of pneumocystis organisms in mice [23]. One previous study suggested that interferon- $\gamma$ was required to suppress Th17 differentiation, and Th17 response seemed to be ineffective to clear pneumocystis infection in immunocompromised mice [24]. The only IL-17 study in human subjects indicated that the levels of alveolar lining fluid IL-17 showed no significant difference between PJP infected patients and two PJP free control groups of patients with or without immunosuppression [25]. However, all the three groups studied included some patients with mixed pulmonary infections. The present study demonstrated that BALF levels of IL-17 in pure PJP and mixed PJP patients were at the lower limit except for one patient and showed no significant difference. Furthermore, the BALF level of IL-17 and IL-23 did not differ between normal controls and either pure PJP or mixed PJP patients (Additional file 3: Table S3). This is in contrast with the previous study showing the IL-23-IL-17 cytokine axis is involved in murine pneumocystis carinii pneumonia [23]. The possible reason is that some inhibitors might depress or neutralize the levels of IL-23 and IL-17. Another one is that IL-23 and IL-17 might occur earlier in the disease course and could not be detected later. The roles of IL-23/IL-17 in PJP and mixed PJP with other respiratory infection patients need further studies to explore.

It is of interest to see the effect of concurrent viral or bacterial infection on the immune dysregulation of PJP, and its clinical relevance in the non-AIDS immunocompromised patients with mixed PJP patients. The results showed no significant differences in the variables measured except for that BALF IL-1 $\beta /$ IL-1RA ratio were significantly higher in bacterial infection subgroup (Additional file 2: Table S2). Because the cases in each subgroup were limited in this study, further studies with larger populations are needed to verify the issues.

Our result showed values of BALF IL-8, IL-8/LL-10 ratio, IL-8/TGF- $\beta 1$ ratio were significantly higher in pure PJP patients with the neede of mechanical ventilation and in deceased patients (Tables 5 and 6). After stepwise logistic regression analysis, BALF level of IL- 8 was the independent factor for the need of mechanical ventilation and BALF level of IL-8/TGF- $\beta 1$ ratio was responsible for the death in PJP of non-AIDS immunocompromised patients. Taken together, BALF inflammatory cytokines or inflammatory cytokines/anti-inflammatory cytokine ratios alone may be not strong enough to serve as prognostic factors. Some other factors including the entities of immunosuppression in non-AIDS immunocompromised patients, associated co-morbidity and severity of
PJP at the diagnosis may be responsible for the need of mechanical ventilation or death of the patients. Further studies with larger populations are needed to verify these issues.

Despite failing to demonstrate the effect of concurrent pulmonary infection on the outcome of non-AIDS PJP patients, the present study confirmed that immune dysregulation did occur in PJP of non-AIDS immunocompromised patients [10]. Accordingly, it is highly suggested that steroid treatment may be indicated in the treatment of PJP of non-AIDS immunocompromised patients to damp the immune reconstruction syndrome or immune restoration disease, which is characterized by a condition of acute pulmonary compromise that is associated with return of immune function in immunocompromised patients with pulmonary infection who were clinically stable prior to the return of immune function, caused by pathogens of PJP [26,27].

\section{Conclusions}

In summary, concurrent infection may cause more severe immune dysregulation of PJP in non-AIDS immunocompromised patients, but has limited effect on the morbidity and mortality of PJP patients. Because of limited number of cases studied, further studies with larger populations are needed to verify these issues.

\section{Additional files}

Additional file 1: Table S1. Comparisons of inflammatory biomarkers in BALF and blood between pure and mixed PJP patients.

Additional file 2: Table S2. Comparisons of cytokines and cytokine ratios in BALF and blood between bacteria and virus subgroups in mixed PJP patients.

Additional file 3: Table S3. Comparisons of IL-17 and IL-23 in BALF among pure PJP patients, mixed PJP patients and normal lung controls.

\begin{abstract}
Abbreviations
PJP: Pneumocystis jirovecii pneumonia; AIDS: Acquired immunodeficiency syndrome; TNF: Tumor necrosis factor; IL: Interleukin; TGF: Transforming growth factor; IL-1RA: IL-1 receptor antagonist; BALF: Bronchoalveolar lavage fluid; CMV: Cytomegalovirus; $\mathrm{PaO}_{2}$ : Arterial oxygen tension; $\mathrm{FiO}_{2}$ : Inspired oxygen fraction; HMGB1: High mobility group box 1; KL-6: Krebs von den Lungen-6; RAGE: Receptor for advanced glycation end product; AGE: Advanced glycation end product; SPD: Surfactant protein D; ICU: Intensive care unit; Th: T helper.
\end{abstract}

\section{Competing interests}

The authors declare that they have no competing interests.

\section{Authors' contributions}

CWC: conception and design, study execution, data analysis and interpretation, drafting and approving of the manuscript. FCL: study execution, data analysis and interpretation. HCT: study execution, data analysis. SCC: conception and design, supervision of study execution, data interpretation, final preparation and approving of the manuscript. All authors read and approved the final manuscript. 


\section{Acknowledgements}

The work was supported by grants from National Science Council of Taiwan (NSC 96-2314-B-010-034-MY3) and grants from Taipei Veterans General Hospita (V100C-060, V101C-026 and V102C-010). The funding sources did not involve in the study design, the data analysis and interpretation, the writing of the manuscript and the submission of the manuscript.

\section{Author details}

'Institute of Clinical Medicine, National Yang-Ming University, Taipei, Taiwan 2Department of Medical Affairs, Taipei Municipal Gan-Dau Hospital, Taipei, Taiwan. ${ }^{3}$ Department of Chest Medicine, Taipei Veterans General Hospital, No. 201, Section 2, Shih-Pai Road, Taipei 112, Taiwan. ${ }^{4}$ School of Medicine, National Yang-Ming University, Taipei, Taiwan. ${ }^{5}$ Department of Nursing, Taipei Veterans General Hospital, Taipei, Taiwan. ${ }^{6}$ Institute of Emergency and Critical Care Medicine, National Yang-Ming University, Taipei, Taiwan.

Received: 16 August 2014 Accepted: 10 November 2014 Published: 19 November 2014

\section{References}

1. Thomas CF Jr, Limper AH: Pneumocystis pneumonia. N Engl J Med 2004, 350:2487-2498.

2. Sepkowitz KA: Opportunistic infections in patients with and patients without acquired immunodeficiency syndrome. Clin Infect Dis 2002, 34:1098-1177

3. Tasaka S, Tokuda H, Sakai F, Fujii T, Tateda K, Johkoh T, Ohmagari N, Ohta H, Araoka H, Kikuchi Y, Yasui M, Inuzuka K, Goto H: Comparisons of clinical radiological features of pneumocystis pneumonia between malignancy cases and acquired immunodeficiency syndrome cases: A multicenter study. Intern Med 2010, 49:273-281.

4. Limper AH, Offord KP, Smith TF, Martin WJ 2nd: Pneumocystis carinii pneumonia. Differences in lung parasite number and inflammation in patients with and without AIDS. Am Rev Respir Dis 1989, 140:1204-1209.

5. Sepkowitz KA: Pneumocystis carinii pneumonia in patients without AIDS. Clin Infect Dis 1993, 17(Suppl 2):416-422.

6. Benfield TL, Vestbo J, Junge J, Nielsen TL, Jensen AB, Lundgren JD: Prognostic value of interleukin-8 in AIDS-associated Pneumocystis carinii pneumonia. Am J Respir Crit Care Med 1995, 151:1058-1062.

7. The National Institutes of Health-University of California Expert Panel for Corticosteroids as Adjunctive Therapy for Pneumocystis Pneumonia: Consensus statement on the use of corticosteroids as adjunctive therapy for pneumocystis pneumonia in the acquired immunodeficiency syndrome. N Engl J Med 1990, 323:1500-1504.

8. Wright TW, Gigliotti F, Finkelstein JN, McBride JT, An CL, Harmsen AG: Immune-mediated inflammation directly impairs pulmonary function, contributing to the pathogenesis of Pneumocystis carinii pneumonia. J Clin Invest 1999, 104:1307-1317.

9. Tasaka S, Kobayashi S, Kamata H, Kimizuka Y, Fujiwara H, Funatsu Y, Mizoguch K, Ishii M, Takeuchi T, Hasegawa N: Cytokine profiles of bronchoalveolar lavage fluid in patients with pneumocystis pneumonia. Microbiol Immunol 2010, 54:425-433.

10. Chou CW, Lin FC, Tsai HC, Chang SC: The importance of pro-inflammatory and anti-inflammatory cytokines in Pneumocystis jirovecii pneumonia. Med Mycol 2013, 51:704-712.

11. Baughman RP, Strohofer S, Colangelo G, Frame PT: Semiquantitative technique for estimating Pneumocystis carinii burden in the lung. J Clin Microbiol 1990, 28:1425-1427.

12. Bozzette SA, Arcia J, Bartok AE, McGlynn LM, McCutchan JA, Richman DD, Spector SA: Impact of Pneumocystis carinii and cytomegalovirus on the course and outcome of atypical pneumonia in advanced human immunodeficiency virus disease. J Infect Dis 1992, 165:93-98.

13. Hayner CE, Baughman RP, Linnemann CC Jr, Dohn MN: The relationship between cytomegalovirus retrieved by bronchoalveolar lavage and mortality in patients with HIV. Chest 1995, 107:735-740.

14. Jacobson MA, Mills J, Rush J, Peiperl L, Seru V, Mohanty PK, Hopewell PC, Hadley WK, Broaddus VC, Leoung G, Feigal DW: Morbidity and mortality of patients with AIDS and first-episode pneumocystis carinii pneumonia unaffected by concomitant pulmonary cytomegalovirus infection. Am Rev Respir Dis 1991, 144:6-9.
15. Miles PR, Baughman RP, Linnemann CC Jr: Cytomegalovirus in the bronchoalveolar lavage fluid of patients with AIDS. Chest 1990, 97:1072-1076

16. Benfield TL, Helweg-Larsen J, Bang D, Junge J, Lundgren JD: Prognostic markers of short-term mortality in AIDS-associated pneumocystis carinii pneumonia. Chest 2001, 119:844-851.

17. Jensen AM, Lundgren JD, Benfield T, Nielsen TL, Vestbo J: Does cytomegalovirus predict a poor prognosis in pneumocystis carinii pneumonia treated with corticosteroids? A note for caution. Chest 1995, 108:411-414.

18. Kim T, Moon SM, Sung H, Kim MN, Kim SH, Choi SH, Jeong JY, Woo JH, Kim YS, Lee SO: Outcomes of non-HIV-infected patients with pneumocystis pneumonia and concomitant pulmonary cytomegalovirus infection. Scand J Infect Dis 2012, 44:670-677.

19. Milner JD, Brenchley JM, Laurence A, Freeman AF, Hill BJ, Elias KM, Kanno Y, Spalding C, Elloumi HZ, Paulson ML, Davis J, Hsu A, Asher Al, O'Shea J, Holland SM, Paul WE, Douek DC: Impaired T(h)17 cell differentiation in subjects with autosomal dominant hyper-IgE syndrome. Nature 2008, 452:773-776.

20. Ma CS, Chew GY, Simpson N, Priyadarshi A, Wong M, Grimbacher B, Fulcher DA, Tangye SG, Cook MC: Deficiency of Th17 cells in hyper lgE syndrome due to mutations in STAT3. J Exp Med 2008, 205:1551-1557.

21. Huang W, Na L, Fidel PL, Schwarzenberger P: Requirement of interleukin-17A for systemic anti-Candida albicans host defense in mice. J Infect Dis 2004, 190:624-631

22. Zelante T, De Luca A, Bonifazi P, Montagnoli C, Bozza S, Moretti S, Belladonna ML, Vacca C, Conte C, Mosci P, Bistoni F, Puccetti P, Kastelein RA, Kopf M, Romani L: IL-23 and the Th17 pathway promote inflammation and impair antifungal immune resistance. Eur I Immunol 2007, 37:2695-2706.

23. Rudner XL, Happel Kl, Young EA, Shellito JE: Interleukin-23 (IL-23)-IL-17 cytokine axis in murine Pneumocystis carinii infection. Infect Immun 2007, 75:3055-3061

24. Hu T, Takamoto M, Hida S, Tagawa Y, Sugane K: IFN-gamma deficiency worsen Pneumocystis pneumonia with Th17 development in nude mice. Immunol Lett 2009, 127:55-59.

25. Iriart X, Witkowski B, Courtais C, Abbes S, Tkaczuk J, Courtade M, Cassaing S, Fillaux J, Blancher A, Magnaval JF, Pipy B, Berry A: Cellular and cytokine changes in the alveolar environment among immunocompromised patients during Pneumocystis Jirovecii infection. Med Mycol 2010, 48:1075-1087.

26. Gigliotti F, Wright TW: Immunopathogenesis of Pneumocystis carinii pneumonia. Expert Rev Mol Med 2005, 7:1-16.

27. Sun $\mathrm{HY}$, Singh N: Opportunistic infection-associated immune reconstruction syndrome in transplant recipients. Clin Infect Dis 2011, 53:168-176.

doi:10.1186/1471-2466-14-182

Cite this article as: Chou et al:: The impact of concomitant pulmonary infection on immune dysregulation in Pneumocystis jirovecii pneumonia. BMC Pulmonary Medicine 2014 14:182.

\section{Submit your next manuscript to BioMed Central and take full advantage of:}

- Convenient online submission

- Thorough peer review

- No space constraints or color figure charges

- Immediate publication on acceptance

- Inclusion in PubMed, CAS, Scopus and Google Scholar

- Research which is freely available for redistribution 